\title{
Naval Engineering
}

\section{A National Naval Obligation}

Chryssostomos Chryssostomidis

Michael M. Bernitsas

David V. Burke, Jr.

MIT OE Design Laboratory Report 2000-9

May 2000 



\section{Acknowledgements}

Many people contributed significantly to this effort, but recognition of the need and having the vision to support this study was among the contributions of Dr. Al Tucker of the Office of Naval Research. Capt. Dennis Mahoney, USN (Ret.) initiated the effort initiated with Dr. Tucker and gave it an initial thrust. Cdr. Cliff Whitcomb at MIT supported the study and participated in many meetings on the subject. Many have contributed input and discussion on the issue, but in particular Dr. Paris Genalis in the Office of the Secretary of Defense has provided significant review and recommendations. Industry and government representatives who attended discussions and provided support and recommendations on the issues are very much appreciated. In particular Dr. Millard Firebaugh (Electric Boat Company), Mr. Matthew N. Greer, Mr. Todd Harland-White, Dr. Marc Paleaz, and Mr. Arnold Moore are appreciated for hosting visits to their companies and meaningful discussions and comments on the subject. Mr. Ron Kiss supported the study by hosting a meeting at Webb and through meetings and discussion. The National Academy was supportive in hosting a meeting for discussion of the subject in DC. Department of education representatives were very helpful in pointing to available information on the web and providing additional information beyond that readily available to breakdown the published summaries. In particular Ms. Aurora D'Amico was very responsive in providing some of the relevant detailed data. The Department of Commerce is conducting a high level study of the industry and Mr. John Tucker and Mr. Steve Baker were very supportive in providing preliminary results to be included in this effort.

Mr. Paul Erb helped arrange the meetings and discussions in Houston. These discussions were very helpful in preparing the study and the efficiency in conducting these visits is very much appreciated. Last, but not least, Ms. Marie Quinn provided administrative support to schedule travel and meetings and contributed to the preparation of the document text.

This project was supported by ONR Contract number N0001499WR20164. 



\section{Table of Contents}

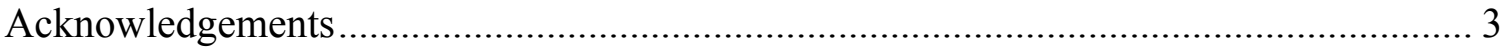

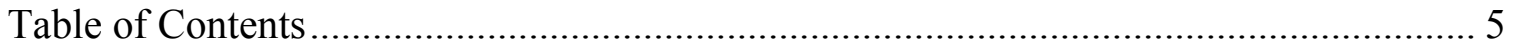

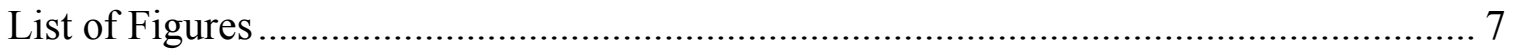

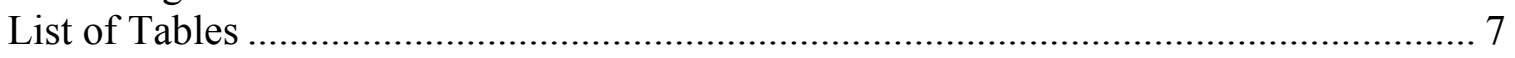

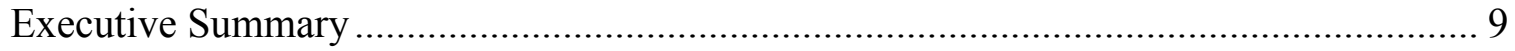

Chapter 1 Charge and Definitions …………………............................................ 11

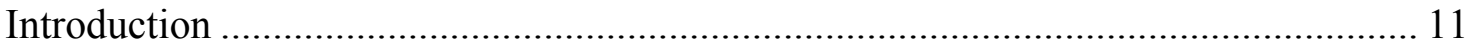

Previous Study Shipbuilding Technology and Education .............................................. 12

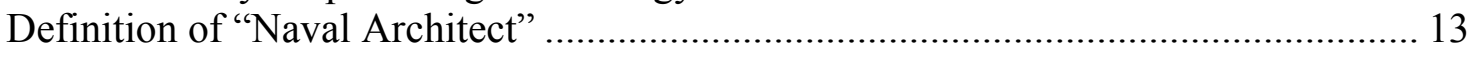

Uniqueness of Engineering for the Marine Environment............................................. 16

Uniqueness of Engineering for the Naval Application................................................ 17

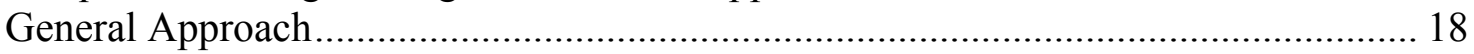

Chapter 2 Current Roles in Navy NA\&ME............................................................ 19

Status and Challenges of the Constituents................................................................. 19

A. Engineering Students................................................................................ 19

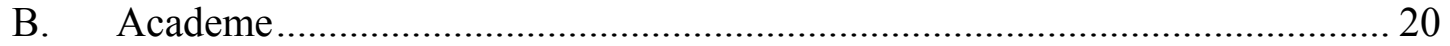

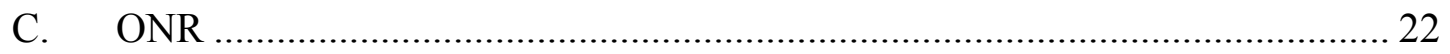

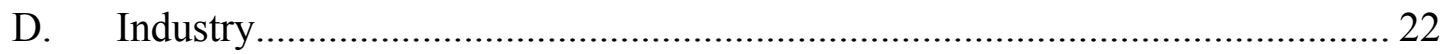

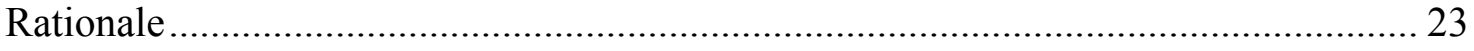

Knowledge of the NA\&ME Professional of the Future .............................................. 24

Challenges of the Constituents: Summary .................................................................. 24

Chapter 3 Universities and Industry: ONR Bridging the Gap.................................... 25

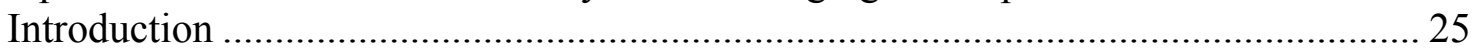

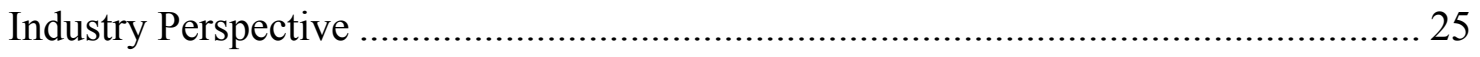

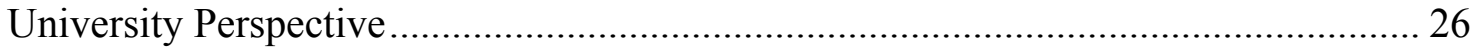

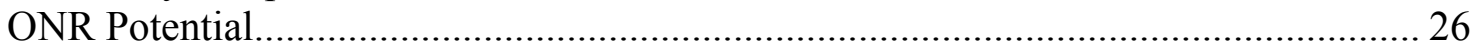

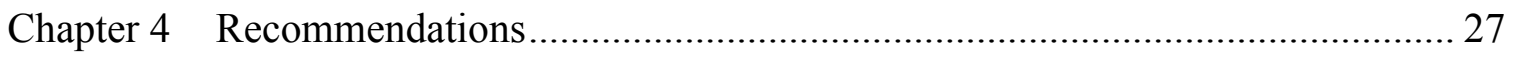

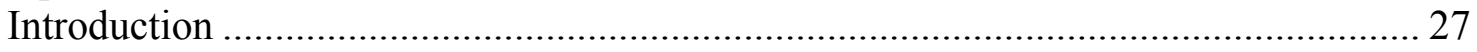

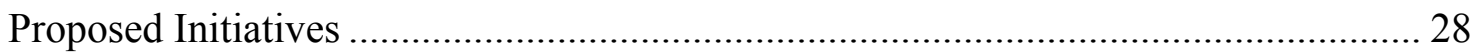

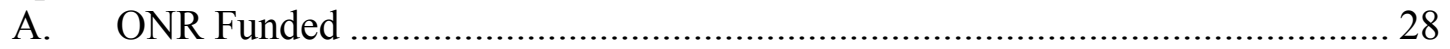

B. Funded by Industry.................................................................................. 30

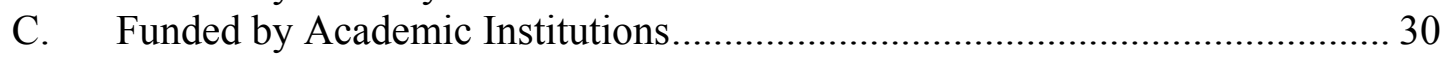

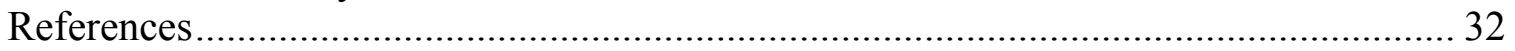

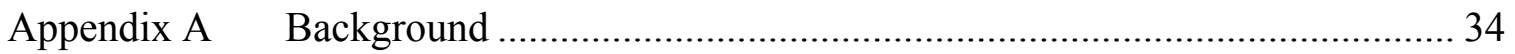

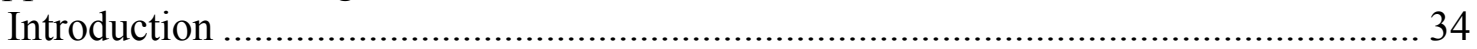

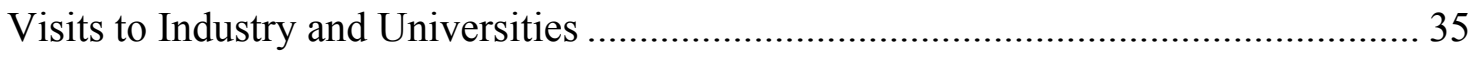

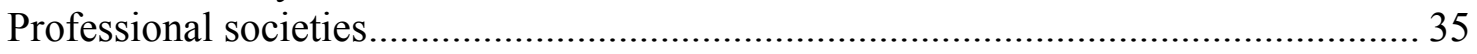

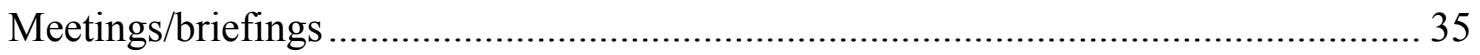

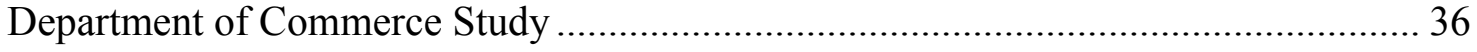

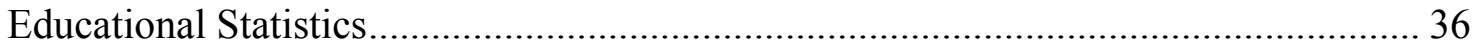

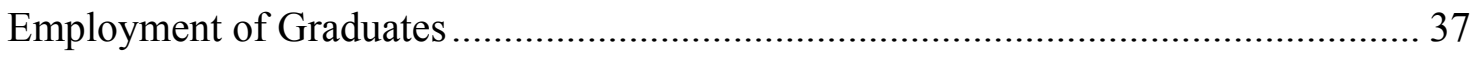

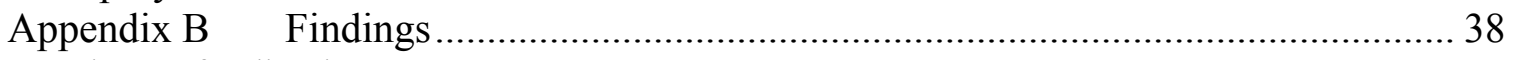

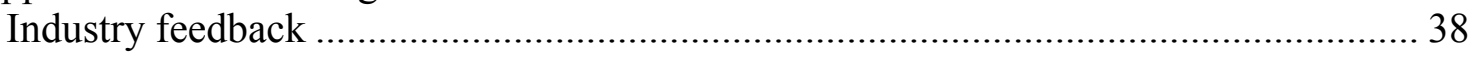


Briefings/Professional Societies

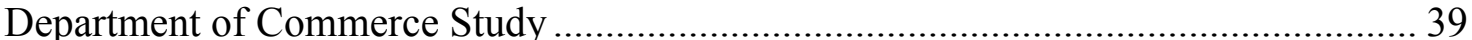

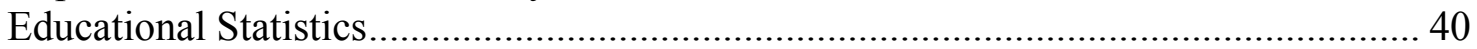

Appendix C National Security Assessment of the Maritime Industry Survey Contents 43

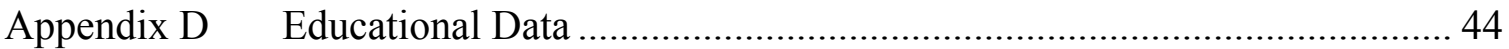

Appendix E Number of Companies Indicating Technology Weakness ......................... 49 


\section{List of Figures}

Figure 1 Knowledge of the NA\&ME Professional of the Future ................................... 15

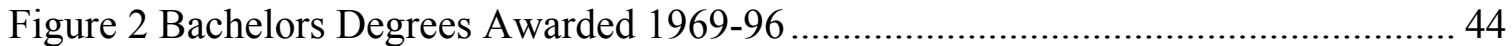

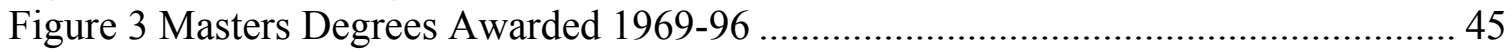

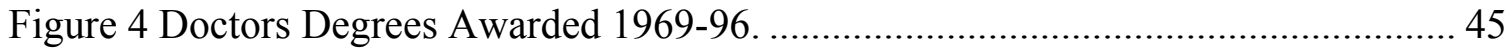

\section{List of Tables}

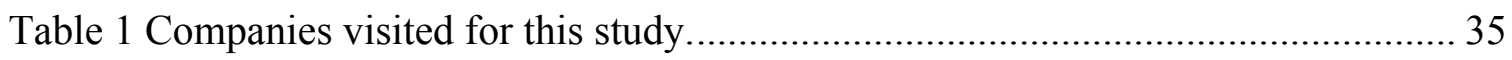

Table 2 Areas Proposed for ONR Research by Industry ........................................... 38

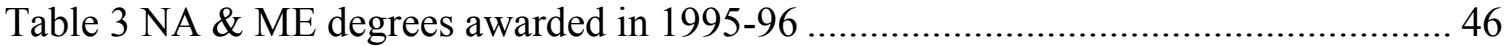

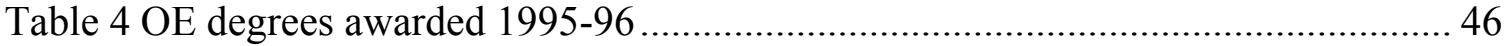

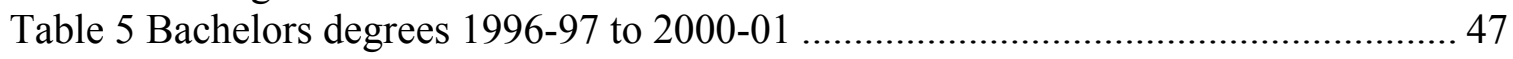

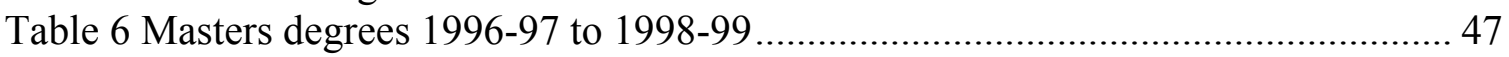

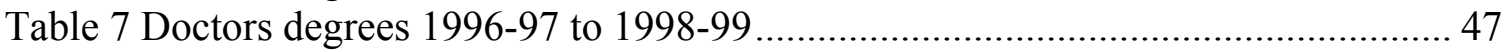

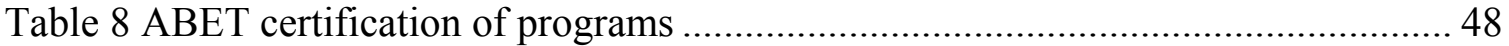





\section{Executive Summary}

As part of its national obligations, ONR must ensure US world leadership in those unique technology areas that insure naval superiority. ONR accomplishes this mission through research, recruitment and education, maintaining an adequate base of talent, and sustaining critical infrastructure for research and experimentation. One critical area requiring support by ONR is the "knowledge infrastructure" in Naval Architecture and Marine Engineering. An innovative knowledge infrastructure in NA \& ME consists of two main elements:

- People who have the knowledge, skills and experience to perform innovative design and engineering applied to in Naval Architecture and Marine Engineering; and

- An industry that employs these people and allows this innovative knowledge to be applied in the ships it designs and builds for the Navy.

The universities along with industry develop the technology and educate the people who are employed by industry. In turn, the research supported primarily by the government provides direct support for the conduct of research and the education of the future faculty who perform their doctoral research in this discipline.

This study examined the current situation in navy related Naval Architecture and Marine Engineering. The need for ONR support in this area is identified and recommendations made to establish long term support that will provide for the introduction of innovative technology in naval ships. The following are documented in this report to establish this need:

(1) The uniqueness of "Engineering for the Marine Environment" is explained. Naval Architecture and Marine Engineering, among all engineering disciplines, studies the design of complex marine systems and their performance in the marine environment. The latter is stochastic in nature and exerts motion and vibration dependent loads.

(2) The uniqueness of analysis, design, and manufacture of naval ships is presented. A key unique aspect of naval ship design is the need for new capabilities in performance such as high speed while remaining affordable.

(3) A vision of the role and knowledge of the NA\&ME professional of the future is presented. In a distributed simulation based environment, naval architects will lead the design effort by contributing the expertise in marine mechanics, design of complex marine systems, and design for manufacturing. Naval Architects are trained in marine mechanics and the design of complex marine systems. This breadth of skills will be even broader in the future while remaining base on experience in designing naval ships. 
(4) The Navy need for a solid national knowledge infrastructure in NA\&ME is established. Accordingly, the need for ONR support of research and education in the few healthy NA\&ME Departments remaining in top tier US universities is very strong.

(5) Navy needs for breakthroughs in such areas as survivability of structures, stealth and hydrodynamic performance, and adaptive structures are identified. From those, fundamental research that naval architects are uniquely qualified to perform for ONR is specified.

(6) A selective industry survey has established the areas of technical expertise needed. Naval Architecture and Integrated Ship Design and Shipbuilding and Manufacturing Technology top the list.

(7) Freshmen in engineering, the few universities remaining active in teaching and research in NA\&ME, ONR, and the shipbuilding industry are the parties involved in this problem. The challenges each party faces are discussed.

(8) The urgency for ONR to help preserve the knowledge infrastructure in NA\&ME is assessed based on current national trends in funding and student choices.

(9) An educated estimate of the national need for naval architects is presented and used as a basis for establishing the level of long term funding in research and education required for a steadily healthy and competitive higher education environment.

(10) An implementation plan for a vigorous knowledge infrastructure and a healthy university environment is proposed. This plan abides by the ONR mandate of supporting fundamental, high risk, innovative research needed by the Navy. It calls for:

- A research program centered on National Challenge Initiatives with the intent to revolutionize the state of the art in ship analysis and design and to bring the participants, industry, government and academia, in this endeavor closer together in perspective and time for innovation.

- Acknowledging NA\&ME as a specialty area of basic research. This is typically done by federal research funding agencies. As an example, in NSF, mechanical, civil, electrical, chemical, etc. are established specialty areas.

- Modernization of contents and methods of delivery of marine curricula.

- Industrial participation in both research and education activities. 


\section{Chapter 1 Charge and Definitions}

\section{Introduction}

Since its creation by Congress over fifty years ago, the Office of Naval Research (ONR) has been charged with the national responsibility of maintaining a vigorous Science and Technology program in areas that are of critical importance to the maintenance of US naval superiority. To discharge this obligation to the nation, ONR has created a number of interlocking strategies that involve research programs in academia, national laboratories and industry. These research programs cover the entire spectrum from basic research serving as the incubator of new ideas to applied research serving as the means of translating research ideas to practice. As described in reference 1: "ONR must ensure US world leadership in those few unique areas through research, recruitment and education, in order to maintain an adequate base of talent, and sustain critical infrastructure for research and experimentation." It is in this context, that this assessment of the "knowledge infrastructure" in Naval Architecture and Marine Engineering (NA \& ME) was undertaken. The phrase "knowledge infrastructure" includes the professional engineering workforce consisting of graduates of relevant university curricula with the required skills and the technology for the people in the marine industry to apply.

An innovative knowledge infrastructure in NA \& ME consists of two main elements:

- People who have the knowledge, skills and experience to perform design and engineering applied to the field; and

- An industry who employs these people and allows this knowledge to be applied in the products it produces

The universities along with industry develop the technology and educate the people who are employed by industry. In turn, the research supported primarily by the government provides direct support for the conduct of research and the education of the future faculty who perform their doctoral research in this discipline.

Government funded university based basic research is one of the strongest engines of innovation in American industry. Naval Engineering is no exception to this rule. Naval Engineering is meant to include Navy related aspects of Naval Architecture and Marine Engineering. ONR university based funding of basic research has been the catalyst that produced some of the key innovations having a profound impact on the Navy's missions. Some of the key advances include remote sensing of ship wakes, propeller design and structural acoustics especially as applied to submarines. Maintaining the university research infrastructure is of paramount importance for ONR to ensure the vibrancy and health of the field for future generations.

Until very recently it was possible to maintain a reasonable university research infrastructure in Naval Engineering with short term and even sporadic ONR 
commitments. In today's highly competitive university environment this is not sufficient. Naval Engineering must compete for resources (faculty, space, dollars and students) with other fields such as computer science and biotechnology. Funding from ONR is particularly important because the US government is the dominant customer for US shipbuilding.

The resource that is most critical is faculty size. In the U.S. only two universities remain that have a viable marine research program that produce a modest number of doctoral degrees. Future faculty in the field will most likely come from these Ph.D. The faculty dedicated to Naval Engineering research is sub-critical even within these two universities. The number of tenure track faculty at University of Michigan is 11 while there are 15 at MIT. Although university administrators understand this problem and would like to contribute towards its solution, they are reluctant to invest additional resources in Naval Engineering until they are convinced that a plan is in place that will ensure the viability of the field.

The need for continuation of innovation in Naval Engineering and the supply of graduates with skills in this discipline is strongly endorsed by the shipbuilding industry. The immediacy of this need was confirmed by an independent national assessment of the industry conducted by the Department of Commerce.

In this study, a plan is proposed to maintain and strengthen the Naval Engineering knowledge infrastructure requiring coordinated and interlocking actions by ONR, industry and academia. The highlights of this proposal are:

- A research program centered on National Challenge Initiatives with the intent to revolutionize the state of the art in ship analysis and design.

- Acknowledging NA\&ME as a specialty area of basic research. This is typically done by federal research funding agencies. As an example, in NSF, mechanical, civil, electrical, chemical, etc. are established specialty areas.

- Modernization of contents and methods of delivery of marine curricula.

- Industrial participation in both research and education activities.

\section{Previous Study Shipbuilding Technology and Education}

This effort is similar in nature and augments a previous study conducted under the auspices of the National Research Council in 1996. Chapter 4 of the report from this study, "National Needs for Education Infrastructure in Maritime Technology", assessed the state of the art of education in naval architecture and marine engineering in the United States and identified steps that should be taken to strengthen the education base. The conclusion and recommendations relevant to the education infrastructure were as follows (briefly stated): 
Conclusion 7: The educational system, which produces the naval architects and marine engineers with a basic understanding of design and materials and the systems thinking needed to design ships, is absolutely essential to the long-term health of the U.S. shipbuilding industry.

Recommendation 6. ONR should continue support of NA \& ME faculty through fellowships, research projects directed at Navy objectives, and to the extent possible, projects with commercial economic impact.

Recommendation 7. NA\&ME schools must become more involved with the U.S. shipbuilding industry through research in business-process, system, and ship production technologies, as well as through soliciting support for these and other kinds of research.

For the complete text of the conclusions and recommendations, see the final report, reference 2.

In view of the changed nature of the national environment, it is appropriate to reexamine many of the issues and questions addressed by this study at this current time.

\section{Definition of "Naval Architect"}

In addressing the potential need to maintain the "knowledge infrastructure" in NA \& ME, it would be appropriate to have a clear well-accepted definition of what it meant by the term Naval Architect. Unfortunately, no such clear consensus exists. The absence of an accepted definition is the subject of a current discussion between the Royal Institution of Naval Architects (RINA) and the Society of Naval Architects and Marine Engineers (SNAME). See reference 3. The view proposed by Larrie Ferreiro is:

"Naval architecture is the application of engineering principles to designing a ship and predicting its behavior and characteristics, so that it will safely and efficiently respond to its element, the sea."

One view of the naval architect, is one who is knowledgeable in one or more of the scientific disciplines associated with the field such as marine hydrodynamics. Typically, the naval architect is also a specialist in a specific discipline of Marine Mechanics. Many in industry hold this narrow view. In addition to this basic knowledge, the naval architect must possess the skills and have the appropriate experience to integrate these individual disciplines into an overall design. A naval ship is one of the largest engineered systems and requires balancing many conflicting requirements, including cost, to reach an overall effective design.

The view for this study is that the Naval Architect must have a deep appreciation of the engineering sciences underlying design of a ship, and is an expert in its overall design. The skill used by the Naval Architect in this activity is referred to as "integration" or "systems engineering". The ability of the Naval Architect to understand all the aspects that affect performance of a naval (or commercial) vessel to enable balancing a number 
of conflicting requirements and achieving an overall satisfactory design. A naval ship is one of the most complex systems to be designed and built. The information necessary to describe that design is far more extensive than other major vehicles or structures.

Even though the field of naval architecture is very broad, new technology continues to extend it even further. Advances in computer tools require application of modeling and simulation both to the specific disciplines such as hydrodynamics but also to integration and systems engineering. Environmental engineering and information technology play a key role in vehicles that operate on the water and need to be connected with many remote vehicles and other systems on land and sea including command and control systems. This view is presented in Figure 1. It is seen that integration of complex marine systems is still central in the skills of a future naval architect with new disciplines forming the total knowledge base. 


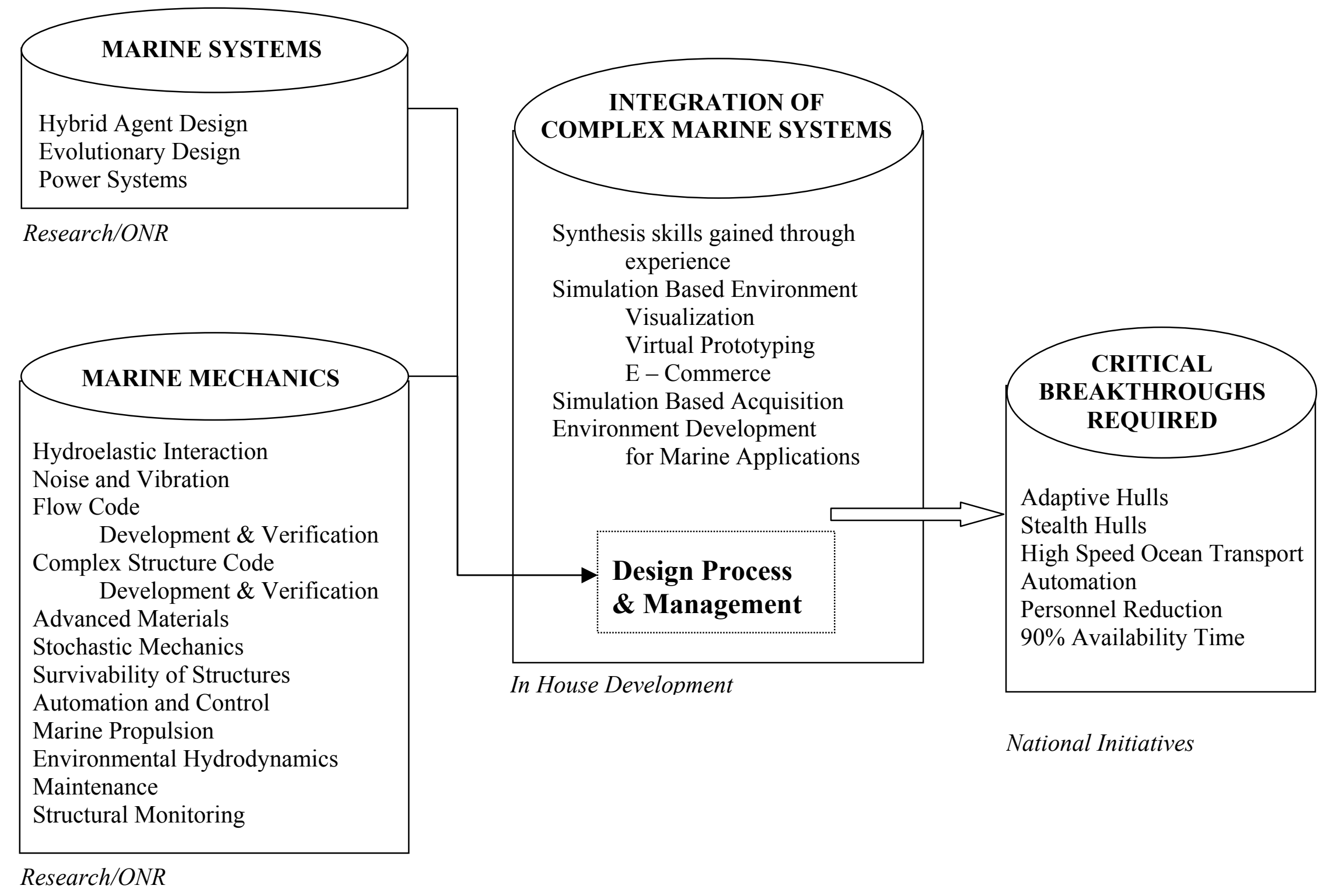

Figure 1 Knowledge of the NA\&ME Professional of the Future 


\section{Uniqueness of Engineering for the Marine Environment}

The marine environment is unique; the structures and vessels operating in the marine environment are unique; the impact of engineering for the marine environment on national prosperity and the quality of human life is very strong.

The marine environment - oceans, lakes and rivers - covers $73 \%$ of the earth's surface. It is unique in the following ways:

- Water is a high pressure medium.

- Salt or fresh water can be highly corrosive.

- Waves can be generated and propagate on the air-water interface.

- Wind generated waves are random and typically form multidimensional spectra.

- Water cavitates when high speeds result in low pressure leading to interfaces within the water medium.

- Marine hydrodynamic problems span a broad range of scales from the smallest dissipative scales of turbulence, through wave and structures scales, to geophysical and mesoscales.

- Electro-magnetic penetration of water is shallow, requiring special communication and sensing for systems operating in and on water.

Marine structures, vehicles and systems are unique:

- Only a small number of each design is built requiring high specialization, and making design for manufacturing more challenging and expensive.

- Marine structures are the largest human-made systems and their databases may be up to three orders of magnitude larger than those of aircraft.

- Marine structures are very complex and structural mechanics problems span a broad range of scales from micro scales for welding and fatigue to full structure scales.

- Marine vehicles and structures operate in and on the ocean thus having special design requirements relevant to seakeeping, capsizing, station-keeping, and random motions and loads in a hostile environment.

The impact of engineering for the marine environment on the quality of life is unique:

- The marine environment is source of food, and clean and renewable energy.

- $74 \%$ of the world trade is carried by ship.

- $95 \%$ of the U.S.A. international trade is transported by ship.

- $50 \%$ of the U.S.A. population lives within 50 miles of a coastline and the number is rapidly increasing.

- Naval ships are essential to national defense.

- $60 \%$ of the U.S.A. energy is imported by ship.

The economic importance of the marine environment makes it a place in which to explore, operate, and utilize its resources. Thus, it attracts engineering operations spanning across all engineering disciplines. The uniqueness of the environment and marine systems, however, require a special discipline within engineering education. 


\section{Uniqueness of Engineering for the Naval Application}

As is developed in the preceding section, the marine environment has many unique attributes. The profession of naval architecture applied to naval ships is termed naval engineering. The naval engineering application has many unique disciplines that go further than those described above.

The American Society of Naval Engineers (ASNE) defines naval engineering as

"NAVAL ENGINEERING includes all arts and sciences as applied in the research, development, design, construction, operation, maintenance and logistic support of surface and subsurface ships and marine craft, naval maritime auxiliaries, ship related aviation and space systems, combat systems, command control, electronics and ordnance systems, ocean structures and fixed and mobile shore facilities which are used by the naval and other military forces and civilian maritime organizations for the defense and well-being of the Nation." Reference 4

ASNE recognizes the increased areas of technology in naval architecture applied to naval engineering by expanding this definition to reflect C4ISR (Command, Control, Communications, Computers, Information, Surveillance, and Reconnaissance), environmental engineering, modeling and simulation, total systems engineering (including the use of commercial components), total ownership costs and information technology. Reference 5.

The disciplines of naval engineering involve skills that are not practiced in other applications. To a degree, general mechanical, civil and electrical engineers have the basic skills to learn the particular unique skilled in naval engineering but expertise in these areas is achieved primarily through specialized education and experience. Some uniqueness aspects of naval engineering follow.

- Naval ships have unique operational requirements:

- Sensing airborne, surface and subsurface threats requires extensive complex extremely capable electronics packaged in a very small platform.

- Naval ships are required to operate over long periods of time in any area of the world.

- They must defend themselves and other forces against actions by opposing forces.

To provide these capabilities, design of naval ship systems is unique:

- Structures must be capable of resisting or sustaining damage while continuing to operate. These include requirements to withstand shock and blast effects.

- Structures must contribute to preventing detection by others without compromise to other demands. This includes non-magnetic and low radar cross section structures.

- Propulsion and structures must be acoustically quiet and have low non-acoustic signatures. 
- Deep diving long endurance submarines utilizing nuclear propulsion and high strength low weight materials have no commercial counterpart.

- Weapons fired from surface and sub-surface platforms place unique demands on both the weapon and the platform.

- The size and complexity of ships incorporating advanced technology in warfighting systems for naval application makes these designs unique.

More important are the unique future requirements pushing the state-of the-art in technology for naval ships:

- Future ships will be required to go at high speeds efficiently

- These ships will require new structural materials to enable lighter weight, and increased stealth and survivability.

- These attributes must be achieved at affordable cost

Even if there were a vibrant commercial shipbuilding infrastructure in the US, many of the above capabilities would exist only in the navy shipbuilding infrastructure and knowledge base. The absence of a commercial non-military infrastructure only increases the uniqueness of these skills.

\section{General Approach}

The general approach followed in this study was to develop answers to three questions posed by ONR at the initiation of this effort: Reference 1

Does ONR need to support Navy NA \& ME?

If YES, what are the core areas of NA \& ME?

What is necessary to sustain and provide advances in those areas?

Input was obtained from a broad spectrum of the industry and educational institutions. Information, opinions and recommendations were received by personal visits, meetings or written and verbal correspondence. These will be further described in later sections. 


\section{Chapter 2 Current Roles in Navy NA\&ME}

To recommend a course of action to ONR, we assess in this chapter the present status and challenges of the constituents and define the vision for the function of the professional N.A\&M.E. of the future.

\section{Status and Challenges of the Constituents}

The four constituents of the NNR challenge are: students entering engineering colleges in the USA, ONR as the representative of the US Navy, a sector of the marine industry (shipbuilding), and NA\&ME Departments in USA universities.

Certain sectors of the marine industry, and particularly shipbuilding of large ships, have been shrinking since the middle 1980's. This has resulted in eroding infrastructure and reduction in human resources. On the other hand, the discipline of "Engineering for the Marine Environment" - referred to in this report as Naval Architecture and Marine Engineering - is broad. It encompasses several engineering disciplines (Offshore, Mechanical, Civil, Electrical, Systems, Economics, Transportation, etc.) as they apply to the marine environment. Further, new challenges in national defense, ocean exploration and resource utilization require more human resources. These two persisting trends lead with certainty to the alarming conclusion that sooner rather than later the USA will lose technical expertise in commercial and naval shipbuilding.

Due to limited resources and limited collaboration, it appears that some interactions between any two of the four constituents are not successful either in input or in product generation. As a result, investments in funds and research and development efforts appear to have limited impact in evolution of the engineering discipline. This observation further alienates the four constituents making the problem more severe.

To develop a viable and sustainable solution, ONR, academe, and industry must collaborate to meet each other's needs and be able to attract high quality engineering students in adequate numbers.

Next, we discuss the position of each constituent separately.

\section{A. Engineering Students}

The vast majority of students entering colleges of engineering do not declare their major until late in their sophomore year. They want to make sure that they find the field that has the following attributes:

(a) It is general enough so that they can find jobs in many different industries. Fields like ME (mechanical), EE (electrical), CS (computer science), chemical, NA\&ME and civil (CE) satisfy this requirement. Student surveys indicate, however, that they are not aware of the generality and breadth of NA\&ME 
(b) It is high tech in the sense of use of computers, visualization, and robots. NA\&ME definitely satisfy this criterion but probably do not have the visibility of other engineering disciplines.

(c) It is easy to find jobs with high salaries upon graduation. In NA\&ME, there are many more jobs per graduate than in most engineering disciplines. CS, however, offers about $\$ 10 \mathrm{~K} /$ year more than the rest of the disciplines.

(d) It is challenging. NA\&ME satisfies this criterion.

NA\&ME is general, high tech, challenging, and provides salaries as high as any engineering discipline but CS. Awareness of what NA\&ME is all about appears to be the major problem in attracting more students. At the University of Michigan (UM) a systematic effort to inform freshmen in the College of Engineering $(\mathrm{CoE})$ has produced satisfactory results; the Class of 2000 has 34 students, the Class of 2001 has 35 students; the Class of 2002 has 39 students.

\section{B. Academe}

The discipline of Engineering for the Marine Environment is broad but the number of students studying this discipline is small. There are only 19 universities with relevant departments or programs. The latter are typically among the smallest in their universities. Consequently, needs of the marine industry are satisfied by ME's, CE's, EE's, CS's, etc. who are not familiar with the unique aspects of the marine environment as summarized in Chapter 1. In contrast, in the old USSR, and now in Russia and the Ukraine, two top quality maritime universities are well established which are as large as entire top tier engineering colleges in the USA. These maritime universities offer most engineering disciplines (ME, CE, CS, EE, etc.) with focus on marine applications, as well as relevant fields, such as maritime economics, shipping, maritime law, etc.

Each department in the USA has focused its activities on very few niches that it can serve best. Those niches focus on a subject such as NA\&ME, offshore, ocean, marine, coastal engineering; or in a level of studies such as BSE, MSE, or research; or a level of student

quality usually dictated by the national competitiveness of the CoE in which the NA\&ME department resides.

The assessment of the challenge described below pertains mostly to research universities which offer the complete spectrum of degrees, perform research as part of their graduate program, and rely on research income for progress and survival. The main components of this challenge are:

(a) Offer all curricula: BSE, 5-year program, MSE, M.Eng, PE Degrees, Ph.D.

(b) Maintain and upgrade expensive and unique experimental facilities: towing tank, design lab, visualization lab with virtual reality, propeller tunnel, small ROV, small AUV, CAD labs, low turbulence free surface channel, etc.

(c) Continually evolve all curricula due to the changing nature of engineering practice and education. 
(d) Quickly implement research products in design at the graduate and undergraduate level.

(e) Compete with CS and ME departments for students and consequently new faculty positions and college resources.

(f) Educate young engineers for a 30-40 year career.

(g) Attract research funding from government and industry. It should be noted that only ONR allocates research funds for NA\&ME. All other agencies such as Sea Grant and NSF have different focus.

(h) Maintain certain level of research funding or lose faculty positions to CS and ME as professors retire or do not make tenure.

(i) Maintain for education and development areas that have been declared mature by ONR and thus have no government research funding.

(j) Provide a mechanism and funding for spontaneous reeducation of faculty. Research areas mature faster than faculty retire while hiring new faculty is a rare occasion for a small department.

To respond to the above challenge, top research universities have:

(1) Focused their teaching on courses that satisfy the unique aspects of Engineering for the Marine Environment as defined in Chapter 1.

(2) Diversified their research targets to find new sources of external funding. This approach further reduces faculty expertise in NA\&ME. A devastating consequence is that faculty interest shifts away from our engineering discipline making teaching of NA\&ME courses even more difficult.

(3) Hired non-tenure/tenure track faculty to teach basic NA\&ME courses.

Top tier research universities need the to do the following:

(i) Attract $\$ 250 \mathrm{~K}$ of external research funding per faculty in analysis and/or numerical modeling.

(ii) Attract $\$ 450 \mathrm{~K}$ of external research funding per faculty in experimental methods.

(iii)Attract $\$ 350 \mathrm{~K}$ per faculty in visualization, computer modeling, and integration of complex systems.

(iv)Maintain comprehensive curricula at all levels by teaching their courses and hiring adjunct faculty to teach the rest of the courses. It should be noted that 12 faculty are not adequate to teach all curricula. As a point of reference, the next size up of engineering departments at the University of Michigan have 18 faculty and fewer students; those are Nuclear, Material Science, and Atmospheric and Oceanic Science.

(v) Meet all the challenges discussed above and present a good alternative to ME and CS to engineering students because there is no way around it in the environment of competitive colleges. 


\section{ONR}

The position of the Office of Naval Research, representing the US Navy in this venture, is as follows:

ONR needs

(a) To maintain basic and applied research capability in NA\&ME to provide innovation for future naval vessels in for the US.

(b) To ensure that US universities produce adequate number of high quality engineers in NA\&ME at all levels; BSE, MSE, PE, and Ph.D to support naval needs.

\section{ONR can:}

(1) Stimulate innovation in naval shipbuilding by funding dual use projects and precompetitive activities that will bring university research into industry. Programs my be either:

(a) High-risk high return research with a vision of 10-15 years. Or...

(b) Development with 2-3 year return.

(2) Fund fellowships at the Ph.D. level.

(3) Not fund undergraduate education directly.

(4) Not fund mature research areas which are needed for development within universities and industry.

The Challenge to ONR is to:

(i) Support a modern NA\&ME discipline that will be able to serve Navy needs.

(ii) Influence the future direction of NA\&ME as a unique engineering discipline, which cannot be served by the other areas of support within ONR.

(iii)Define research areas unique to NA\&ME so that universities in this discipline can perform research compatible with the mission of ONR.

(iv)Lead the development of a National Challenge Initiative

\section{Industry}

The shipbuilding industry worldwide is operating under a profit margin of only $3 \%$. It is also speculated that in several countries strong subsidies are in place. This competitive, low margin return environment allows for little investment in long term research.

Accordingly, the interaction between universities and the shipbuilding industry has been the lowest among engineering industries and universities. Other sectors of the marine industry, such as the offshore industry, have been more supportive of university research. This industrial viewpoint with its focus on immediate component problems of a specific design has resulted in lack of long term 6.1 research in the shipbuilding industry and lack of interest and expertise among faculty. 
Interaction between ONR and the shipbuilding industry in 6.1 research has also been limited. The nature of the problem is probably similar to that between research universities and the shipbuilding industry.

On the other hand, shipyards continuously ask for BSE's tailor trained to their immediate needs while top tier universities aim at educating engineers for a 30-40 year career. Some symptoms of this gap between the expressed needs of industry are the expectation of hands on familiarization with computer packages in use in the industry. Many of today's brightest students are capable of learning typical computer tools in a relatively short time on the job. Universities attempting to attract students to the field need to challenge the students with advanced theoretical concepts which better prepare them for future intellectual growth. Today's curricula also demand many courses oriented towards the developing understanding, maturity and capabilities needed to meet the challenges of modern society.

Another aspect of the US shipbuilding industry is the dominance of the naval portion compared with the commercial. In the U.S., ship design and shipbuilding of large ships is dominated by a single customer, namely, the U.S. Government. It is estimated that about $90 \%$ of the $\$ 26$ billion of U.S. shipbuilding in this country is done for the U.S. Government and most of it for the U.S. Navy. (Reference 6). While government shipbuilding is an overwhelming majority, the design activity is not at a high level. As reported in reference 7, "24 designs for are in progress for 193 ships. Many high value designs may be designed once and then built for 15 years." The implications of this are that the great majority of engineering talent is engaged in detail design and the threshold for innovation is high due to the lack of multiple designs so the acceptance of one failure is very low. The shipbuilding company's IR\&D will not be invested in major innovative concept design development, as there are too few opportunities for a return on that investment. This inhibits innovation. In contrast, in the commercial sector, "65 different designs (have been) developed for 95 vessels under construction. Design activity is continuous as most projects are designed and built in 1-2 years."

In a part of the commercial sector, there is extensive innovation on a smaller scale. The recreational boat industry has long used fiberglass and other non-metallics in hull construction as one example. The small size of the companies engaged in this sector precludes both the investment in general research and development and in contributing to the general naval architecture knowledge infrastructure by publishing papers or attending professional technical society meetings. The desire for competitive advantage in this sector overwhelms any benefit to sharing knowledge in a wide audience.

\section{Rationale}

There are many conflicting requirements in this puzzle. Instead of discussing the obvious conflicts, this report focuses on the following approach: 
(1) Define the discipline of Naval Architecture and Marine Engineering. Establish the uniqueness of the discipline. Define the unique knowledge that engineers educated in NA\&ME bring to the process of integration (analysis and design) of a marine system.

(2) Prepare a list of university facilities that are unique nationally and should be maintained for education and research; e.g. marine hydrodynamics lab, structures lab.

(3) Establish an ONR advisory panel with University participation to define annually research priorities, student production rates, required national breakthroughs in ship technology, etc.

(4) Set up large and long-range projects to achieve impact.

(5) Develop links to potential industry users so that they can appreciate the developed technology and look forward to hiring new Ph.D. graduates.

(6) Ensure that faculty implement research products into the SBE environment and the curricula (Ph.D., MSE, BSE) quickly so that an impact on education is achieved.

(7) Facilitate periodic reeducation of faculty to pursue new CP projects. This is important in view of the fact that technology matures faster than faculty retire and hiring of new faculty in small departments is not a frequent event.

\section{Knowledge of the NA\&ME Professional of the Future}

The engineering profession, practice and education are changing rapidly as discussed in reference 8. A first element in the above rationale is to envision the role of a naval architect and marine engineer in the future.

The NA\&ME professional of the future educated in a top tier USA research university will have the skill to integrate marine systems in a distributed Simulation Based Environment. The education/knowledge he/she will contribute to the process is understanding of the uniqueness of the marine environment, the uniqueness of the marine product and its manufacture as well as its performance in such an environment (see Chapter 1). At the research level, the NA\&ME professional will lead in certain marine mechanics areas and in marine system design. Figure 1 in Chapter 1 depicts this vision.

\section{Challenges of the Constituents: Summary}

As described above, the three major constituents of the knowledge infrastructure in NA\&ME have different views on the problem. All are highly motivated to succeed in the future from their own perspective. There are many potential actions that could be undertaken, but perhaps the most beneficial for the future could be for ONR to initiate programs oriented toward bridging the gap between industry and academia in the long term versus shorter term view. The next chapter will expand on this potential. 


\section{Chapter 3 Universities and Industry: ONR Bridging the Gap}

\section{Introduction}

The nature of shipbuilding in the US presents major challenges to maintain a vibrant and innovative industry. As seen previously, the government is the primary customer for the major shipyards. Affordability has demanded fewer designs to accompany the reduced numbers of naval ships. At the same time, increased performance effectiveness is expected resulting from investments in research by ONR. This situation presents a major opportunity to initiate activities which will close the apparent gap between the long term view needs of universities and the shorter term requirements from industry.

\section{Industry Perspective}

Current shipbuilding programs tend to be for few new designs and small numbers. The limited competition and low tolerance for risk taking, forces industry to concentrate on more details of an existing design than exploring new innovations for new concepts. It is unlikely that an investment in something radically different will stand the budget and risk averse decision process in authorizing new shipbuilding programs. While undoubtedly enthusiastic about making major innovations, their needs are driven to today's needs to deliver an affordable ship with low risk to cost or performance. Hence the industry is reluctant to sponsor long term research and growth of new faculty at universities. Visits and discussions with industry representatives resulted in recommendations for future research work that tended to be focussed on current program needs. See Table 2 in Appendix B. Virtually all companies visited were anxious to hire NA\&ME graduates with undergraduate and graduate degrees.

Industry and in particular, the Society of Naval Architects and Marine Engineers have expressed concern over the apparent demise of shipbuilding design education in the US. A workshop was convened at Webb Institute in January 2000 to address this issue. Many attendees indicated a perception of recent graduates lacking the required skills to immediately practice the engineering required in current naval shipbuilding programs. This phenomenon will worsen without investment in future faculty who can properly educate future students in the appropriate disciplines of naval engineering.

Naval programs are the major fraction of shipbuilding currently in place. These programs have been driven by decisions that emphasize affordability. To achieve this requirement, the number of designs is limited to achieve cost savings by building multiple versions of the same design and basing these designs on past practice. See reference 7. Large scale innovation is hindered in this risk averse environment because an industrial bidder cannot afford proposing a high risk program, even with the potential for high payoff. 


\section{University Perspective}

As described above, universities are faced with maintaining expensive facilities and more significantly, hiring and developing new faculty to perform innovative research and educate future students. This must take place in a very competitive university management environment where other upcoming disciplines such as biological and information engineering are competing for new faculty positions. Even if financial support exists, it is not automatic that NA\&ME will prevail when seeking to hire new faculty. An industry constituency and potential for significant research contribution are required.

Competition for the brightest students is also very keen. The lure of exciting and very rewarding jobs in software development attracts many of the best and brightest students. Traditional NA\&ME is perceived as mature and unexciting with an industry only interested in hiring engineers to perform detail engineering of mature designs. Even students who choose to major in the field are often attracted to employment in unrelated or at best peripheral to the central disciplines of NA\&ME. One such area recently has ben in the financial industry.

Faculty research needs to focus on major new ideas and concepts. While it is appreciated that shipbuilders face many difficult challenges, not many of them appear competitive when major faculty hiring decisions are made.

\section{ONR Potential}

In light of the different perspectives of industry and universities in the field of NA\&ME, there is presented a major opportunity for modest investment by ONR to address both of these constituents and insure the future capability of designing innovative and effective future ships for the navy. An initiative that involves industry in a substantive way and creates an environment of exciting and challenging innovative research will meet the needs of the universities and provide the talented and skilled engineers in the future. Students will be attracted to disciplines offering exciting and challenging research and to the field that is innovative and future oriented. These university graduates will be the knowledge infrastructure in both quantity and quality necessary for the naval fleet of the new century. 


\section{Chapter 4 Recommendations}

\section{Introduction}

To be effective in maintaining and improving the knowledge infrastructure in the field of Naval Architecture and Marine Engineering, actions must be initiated that strengthen the two principal constituents of the field. That it must:

- Continue to educate the people who will have the knowledge, skills and experience to perform design and engineering applied to the field; and

- Meet the needs of the industry that employs these skilled people and allows this knowledge to be applied to the ships it designs and builds for the Navy.

Academic departments with educational programs in Naval Architecture and Marine Engineering are responsible for the education of ship designers and shipbuilders of tomorrow. The strength of a good Naval Architecture and Marine Engineering education is its in depth exposure to all the engineering science needed to design ships and its excellent track record of teaching system design especially of complex systems such as ships. This particular aspect of university-based education is of extreme importance to our Navy considering the central role ships play in our Navy's mission. The significance of educating young engineers in overall design of ships (and by extension of other complex structures) was identified in our industrial interviews as the most valuable contributions of Naval Architecture and Marine Engineering education.

Academic departments with research programs in Naval Architecture and Marine Engineering or the broader field of Ocean Engineering are responsible for some of the key innovations that had a profound impact on the Navy's mission. The innovations cover the wide breadth of the fields and have made significant improvements in operational performance. A partial list includes:

- Propeller design and analysis that contributed to 10 to $20 \mathrm{~dB}$ decrease in ship's radiated noise

- An integrated product and process environment that enables us to derive a comprehensive understanding of ship design and fabrication processes

- Advanced welding techniques to join thick submarine hull sections with no or minimal rework

- Identified several fundamental mechanisms involved in remote sensing of ship wakes

- Identified several fundamental hydrodynamic and electromagnetic mechanisms responsible for active remote sensing of ocean surface phenomena 
- Innovation in structural and underwater acoustics which led to more quiet and more capable submarines.

These innovations are typical of the broad scale of activity in naval engineering. The examples listed span the sub system application; e.g. propeller design and welding thick submarine sections to a much larger scale system application such as remote sensing of ship wakes. The innovations affect more than ships. Current research, if properly nurtured, promises to continue the excellent track record of earlier sponsored naval engineering research. One such area is the concept of vorticity control, which promises to provide marked improvements in ship performance and ship maneuvering. Another area is the development and verification of hydrodynamic codes for implementation in hull design

Strong research programs intimately involved in the Navy's mission also provide the experts needed to help develop the new Navy systems that will affect the Navy's mission capabilities for the foreseeable future. One such area is the new sonar design and the strong involvement of academics from the conceptual design to its implementation. Another example is the development and verification of structural dynamics codes for implementation in hull design

An academic discipline, especially in today's highly competitive university environment must have a strong student body, a vigorous research program and modern infrastructure if it is to retain its vibrancy and compete successfully for faculty, space, dollar resources and students. Research does not have to be undertaken in all universities engaged in a particular discipline but must be present in a few carefully selected departments to ensure the growth and renewal of the discipline.

Above, we have argued the importance of research if it is to maintain Naval Architecture and Marine Engineering as an academic discipline in this country capable of serving the Navy's needs. Since shipbuilding in this country has essentially a single customer, the U.S. Navy, it becomes the responsibility of ONR to provide resources to ensure a strong research program in at least a few universities. The unique needs of the naval ship to operate at high speed with significant payload while remaining stealthy and affordable present opportunities for development of significant new capability.

A program of national responsibility is outlined below. It contains elements of ONR, industry and academia's responsibility in pursuing these opportunities.

\section{Proposed Initiatives}

\section{A. ONR Funded}




\section{National Challenge Initiatives (NCI)}

Establish a number of large projects to address key issues in Naval Engineering with the intent to revolutionize the state of the art in ship design. The projects would be the result of National Challenge Initiative generated by the community and would be multidisciplinary in nature. Industry and multiple universities should have substantive participation. The projects would be focussed on the needs and opportunities in naval ship design and shipbuilding. It is expected to satisfy the needs of all the constituencies of navy NA\&ME. The future operational needs of the navy will be met with new and innovative technology offering improved performance at affordable cost. Students should be excited about the challenges offered and the naval engineering discipline can attract students for future employment who would gravitate to the computer and information industry as they do now. The graduates of universities involved in these programs should find it straightforward to continue working in the industry that is involved and committed to this new technology. The Ph.D. graduates from these initiatives will provide the core of research and development entities in government and industry and some will become the future faculty maintaining the long-term knowledge infrastructure. It is recommended that ONR initiate one or two new projects each year.

\section{Graduate Traineeship Awards}

Establish awards for study and research leading to a doctoral degree, to be given to individuals who have demonstrated a special aptitude and desire for advanced training in Naval Architecture and Marine Engineering. The awards should be 36 months in duration and should cover the student's full tuition, stipend and required fees. Recommend we initiate five new graduate traineeships per.

\section{Postdoctoral Fellowships Awards}

Establish awards to be given to outstanding Ph.D.s who wish to continue research in Naval Architecture and Marine Engineering or related disciplines. These awards should be 24 months in duration and should cover full salary and benefits. Suggested three to four awards per year.

\section{Faculty Industrial Traineeship Awards}

Establish awards to be given to interested faculty who wish to apprentice in shipyards or other related companies. The major benefit of this program is the two-way technology transfer between universities and industry. These awards should be one month to one year in duration and should cover full salary and benefits. Suggested one to two new awards per year.

\section{Establishment of a Workshop on Naval Ship Innovation}

This workshop would convene at least annually to assess the health and balance of Naval Architecture and Marine Engineering Science and Technology and advise ONR 
management of any important issues. Key participants should be involved continuously in the research and development efforts of the NCI and the industry. Participants should represent the universities engaged in Naval Architecture and Marine Engineering research and from the community at large.

\section{B. Funded by Industry}

\section{Participation in National Challenge Initiatives}

Participate in the formulation, funding and technology transfer of National Challenge Initiatives. The level of involvement will depend on the level of funding. Participation at the minimum will insure attendance in the quarterly meetings and support of an undergraduate student and full participation will allow participation in problem definition and support of a graduate student.

\section{Industrial Sabbaticals}

Fund part time or full time sabbaticals to allow industrial staff to participate in teaching and research activities of the host educational institution. Such an appointment could be part time for an extended period of time or full time for shorter periods of time.

\section{Career Awareness Seminars}

Sponsor such events as career fairs at educational institutions to promote the field. Participate in seminars and recruit actively in universities. Establish close relationships with at least one faculty member in each of the major educational institutions with Naval Architecture and Marine Engineering Programs.

\section{Student Traineeship Awards}

Establish awards for both undergraduate and graduate students to spend time in industrial settings and engage them in meaningful tasks in the Naval Engineering Profession.

\section{Funded by Academic Institutions}

1. Incorporate research from the National Challenges Initiatives in the curriculum

Academic institutions transfer and maintain the research products generated from the National Challenges Initiatives in the curriculum as soon as possible. The cost of this transfer will be funded by the academic institutions. 


\section{Coordination Among Academic Institutions}

Academic institutions involved in Naval Architecture and Marine Engineering will organize themselves to meet once a year to exchange information and where appropriate materials, coordinate effort to minimize unnecessary duplication and identify crucial issues affecting the community at large. We propose that this event be held in conjunction with the SNAME annual meeting and costs associated with any development associated with this activity will be absorbed by the academic institutions themselves.

\section{Continuing Education}

Academic institutions agree to survey industry to determine what is necessary for the continuing education of the Naval Architecture and Marine Engineering workforce. The objective of this continuing education effort is to develop and maintain the necessary educational materials to contribute to a lifelong education so necessary in today's rapidly changing environment. A principal ingredient of the material included in the continuing education project is material generated in the National Challenge Initiatives and other improvements derived from the regular academic institutions.

\section{Maintain infrastructure}

All university programs engaged in National Challenge Initiatives develop strategic plans to promote faculty increases in the area of Naval Engineering to the university administration, improvement of the academic infrastructure in the form of staff and specialized facilities, recruitment of students and increased interactions with industry.

The resulting reports will be updated on an annual basis. 


\section{References}

1. Presentation by Dr. Al Tucker at university/industry meeting, MIT May 14, 1999.

2. Shipbuilding Technology and Education, Committee on National Needs in Maritime Technology, Marine Board, Commission on Engineering and Technical Systems, National Research Council; National Academy Press 1996.

3. Ferreiro, L. D., "A Definition of Naval Architecture”, Marine Technology, Vol. 36, No. 4, Fall 1999, pp.xiv-xv.

4. American Society of Naval Engineers (ASNE) web site: http://www.navalengineers.org/

5. Proposed changes to ASNE's bylaws, 2000 election ballot.

6. Marine Log website: http://www.marinelog.com/DOCS/colfeb1.html

7. Presentation by Peter Noble (American Bureau of Shipping) at SNAME Seminar: Education in Ship Design, January 16-18, 2000 at Webb Institute; "Some Thoughts on the Current System and on Future Opportunities"

8. M. M. Bernitsas, "Engineering for the Marine Environment at a USA Research University," Proceedings of MEET'99, Maritime Engineering: Education and Training, Saint Petersburg, Russia, June 21-24, 1999.

9. National Security Assessment of the Maritime Industry, Industry Survey: Building and Repairing of Ships, Boats, and Other Marine Platforms, A Joint Project Between the U.S. Department of Commerce, Bureau of Export Administration and the U. S. Department of the Navy, Naval Surface Warfare Center, Carderock Division. September 1999

10. U.S. Department of Education. National Center for Education Statistics. Chartbook of Degrees Conferred, 1969-70 to 1993-94, NCES 98-071, Thomas D. Snyder, Project Officer. Washington DC: 1997. URL: http://www.nces.ed.gov/pubsearch/pubsinfo.asp?pubid=98071

11. U.S. Department of Education, National Center for Education Statistics, [E.D. Tabs] Degrees and Other Awards Conferred by Degree-granting Institutions: 1995-96, NCES 98-256, by Frank B. Morgan, Washington, DC: 1998. URL: http://www.nces.ed.gov/pubsearch/pubsinfo.asp?pubid=98256

12. Hitoshi Narita and Philip Koenig, Shipbuilding and Ocean Technology, Asia Pacific Region, R\&D Newsletter, SRD \#3, Nov. 1999 
13. University of Michigan website: http://www.engin.umich.edu/dept/name/jobs/

14. Office of Strategic Industries and Economic Security, US Department of Commerce, Maritime Summary; received by fax December 28, 1999

15. National Science Foundation, Division of Science Resources Studies, Science and Engineering Doctorate Awards: 1997, NSF 99-323, Author, Susan T. Hill (Arlington, VA 1999). URL: http://www.nsf.gov/sbe/srs/nsf99323/

16. National Science Foundation, Division of Science Resources Studies, Graduate Students and Postdoctorates in Science and Engineering: Fall 1997, NSF 99-325, Project Officer, Joan Burrelli (Arlington, VA 1999). URL: http://www.nsf.gov/sbe/srs/nsf99325/

17. From: karen bricker@PCCI.COM Date: Mon, 27 Sep 1999 14:11:38 -0700 To: DVBurke@MIT.EDU Subject: NEDRC Request; Sent at request of "D'Amico,Aurora" < Aurora_D'Amico@ed.gov>

18. Date: Mon, 15 Nov 1999 13:00:11 -0600 From: William Vorus wvorus@uno.edu Subject: Data re ONR study To: dvburke@MIT.EDU

19. From: Wayne Neu neu@vt.edu To: "'Dave Burke'" dvburke@MIT.EDU Subject: RE: Request for some data re ONR study Date: Tue, 2 Nov 1999 14:28:42 -0500

20. From: "bmurray" bmurray@webb-institute.edu To: dvburke@MIT.EDU Cc: "Compton, Roger" <rcompton@webb-institute.edu>, "Ron Kiss" rkiss@webbinstitute.edu Subject: Statistics on degrees Date: Thu, 4 Nov 1999 10:27:06 -0500

21. From: "bmurray" bmurray@,webb-institute.edu To: "Dave Burke" dvburke@MIT.EDU References: 2.2.32.19991105001951.008fdc6c@po7.mit.edu Subject: Re: Statistics on degrees Date: Fri, 5 Nov 1999 08:46:34 -0500

22. Sender: michaelb@srvr5.engin.umich.edu Date: Tue, 9 Nov 1999 11:21:10 -0400 To: dvburke@MIT.EDU From: "Michael M. Bernitsas" michaelb@engin.umich.edu Subject: Re: Request for some data re ONR study

23. From: "Edwin Wiggins" ewiggins@optonline.net To: "Burke, Dave" dvburke@MIT.EDU Subject: ABET Accredited Programs Date: Mon, 4 Oct 1999 20:00:38-0400 


\section{Appendix A Background}

\section{Introduction}

An initial meeting of approximately 20 representatives of industry, government and academia took place at MIT on May 14, 1999. ONR presented an overview of the mission of ONR and the potential for a National Naval Program to maintain the Navy unique science and technology (S\&T) areas that will support future ship design and development. These include:

- A robust research capability

- An adequate pipeline of new scientists and engineers in disciplines of unique Navy importance

- Providing the science and technology products necessary to ensure future superiority in integrated naval warfare

Such a program should be consistent with overall Hull, Mechanical and Electrical (HM\&E) S\&T objectives:

- Improved performance

- Design flexibility

- More affordable increased survivability

Skills that can be transferred from other supported disciplines should not be emphasized compared to those areas that are unique to Navy NA \& ME. Examples of transferable skills include structural design and analysis that would be supported by the civil and mechanical engineering infrastructures and elements of hydrodynamics that could be transferred from the aircraft industry. On the contrary, the fluid structure interaction problem, which includes structural acoustics, is unique to the NA\&ME discipline.

Three questions were posed to address this issue:

Does ONR need to support Navy NA \& ME?

If YES, what are the core areas of NA \& ME?

How much will it take to support those areas?

To address these questions, MIT was asked to conduct and coordinate visits to industry and meeting with government and academic representatives to seek their input and recommendations. A summary report (this document) describing these efforts and offering a set of recommendations would be prepared. 


\section{Visits to Industry and Universities}

To stimulate and focus the discussion with industry leadership during visits to their plants, a questionnaire was developed and forwarded in advance. The discussions were focused on the following issues:

- Expectations for the skills of a bachelor degree engineer starting work at their company. Was it essentially required to have a graduate degree to be useful?

- Expectations for the skills of a master degree engineer starting work at their company.

- How effectively did they incorporate results from the university research programs? What new areas might be proposed for future research?

The companies visited are listed in Table 1:

Table 1 Companies visited for this study.

Northrop Grumman (Annapolis, Md.)

Newport News Shipbuilding

Electric Boat

Webb Institute

Ingalls Shipbuilding

ABS

University of Michigan
Aker Engineering*

BP/Amoco*

EXMAR Offshore*

Exxon Production Research*

Global Marine Drilling*

Modec International LLC*

Shell E\&P Technology*

* hosted by Exxon Production Research

\section{Professional societies}

The Society of Naval Architects and Marine Engineers (SNAME) and the American Society of Naval Engineers (ASNE) were asked to provide input to this effort. Upon the advice of the respective president of each society, the Advisory Public Service and Technical and Research committees of SNAME were contacted and written input from ASNE was obtained. The annual meeting of SNAME also provided an opportunity to brief interested parties during the meeting in Baltimore, $\mathrm{Md}$.

\section{Meetings/briefings}

Complementing the visits to industry, a meeting was held in Washington D.C. at the National Academy with key members of industry, academia and government. Discussion followed a presentation containing some specific information on the educational environment and situation at US universities using MIT as an example. It was recommended that broader information be obtained and out of this meeting came a recommendation to present the issue to a subset of the Defense Science Board for a high level independent review of the issue.

A meeting with three members of the Defense Science Board (DSB) was held on November 5, 1999. Dr. John Foster. Mr. Alan Ellinthorpe and Dr. John Stenbit were present with ONR (Dr. Al Tucker) Office of the Secretary of Defense (OSD) (Dr. Paris 
Genalis), representatives of industry (Dr. Millard Firebaugh) and academia. Prof. Michael Bernitsas of the University of Michigan and Prof. Chryssostomidis of MIT presented information and potential recommendations to address the issue.

\section{Department of Commerce Study}

In parallel with this study, a major National Security Assessment of the U.S. Maritime Industry is in progress. It is a joint project between the U.S. Department of Commerce, Bureau of Export Administration and the U. S. Department of the Navy, Naval Surface Warfare Center, Carderock Division. See reference 9. Many other government and industry representatives are involved. The study is very comprehensive. The overall objectives are to:

1. Illustrate the relationship between the maritime industry, national security, and the vitality of the US economy.

2. Identify opportunities for increased sharing of marine science and technology between public and private entities.

3. Improve the use of public maritime capabilities toward advancing private industry competitiveness.

4. Encourage cooperative efforts within the maritime industry between government, industry, and academia.

The initial segment is directed at the maritime industry. This includes companies involved in building and repairing of ships, boats, and other marine platforms. It is expected that the results of this survey will be available early in 2000. The contents of the survey are listed in Appendix C. It is planned to be followed by a number of other surveys, the first of which will assess the Marine Technology and Education sector.

The sections of the study that identify Labor Skill Shortages and Maritime Technology and Development Needs are indicative of current problems in the NA \& ME infrastructure at the present time. Companies were requested to identify labor shortages of marine professionals with skills in Naval Architecture and Marine Engineering in addition to others. In the section technology, the industry has been asked to identify marine technology and development needs in the areas of Naval Architecture and Integrated Ship Design and Support and Shipbuilding and Manufacturing Technology. These are directly related to the assessment of the "knowledge infrastructure" in NA \& $\mathrm{ME}$ at the present time. It can serve as an indicator of the needs in the future. The interim results of this survey will be reported in the following section on findings.

\section{Educational Statistics}

The U.S. Department of Education, National Center for Education Statistics collects extensive data and reports statistics on U.S. education. Tables 15 through 40 of the Chartbook of Degrees Conferred, 1969-70 to 1993-94 provides numbers of bachelor, 
master, and doctor degrees conferred by institutions of higher education, by field of study for the academic years 1969-70 through 1994-95. See reference 10. Data for subsequent years was obtained from Table 10 of reference 11.

Data reporting the degrees awarded over the period from 1970 through 1999 and a listing of universities with accredited programs in the field are shown in Appendix D.

No formal comparison of foreign programs was conducted as part of this effort. However, a recent report from the ONR International Field Office Asia described the academic situation in Korea. Reference 12 in its review of academic institutions reports that 12 universities in Korea have departments of naval architecture. There are 94 professors and approximately 600 naval architects are graduated each year. The Koreans are concerned about a decrease in the number of naval architecture graduates who enter the shipbuilding field as students tend to favor careers in high growth industries such as the automotive industry and information technology. This is a phenomenon also evident at MIT. Students who pursue Ocean Engineering typically had a strong interest in the water since childhood. The challenge in the universities is to retain these individuals and attract others by creating the impression (and reality) of engineering in the ocean as an exciting and stimulating field.

\section{Employment of Graduates}

An exhaustive study of where NA\&ME bachelor degrees find employment was not undertaken. Based on reports from the University of Michigan and described on their website, (reference 13) there is a wide spectrum of companies that employ undergraduates in the field. Verbal inputs from the University of New Orleans and Virginia Polytechnic Institute indicate no difficulty finding a position in the industry. MIT's program in Ocean Engineering is less oriented towards the shipbuilding industry and the graduates have found positions in diverse industries including Walt Disney (robotics) and financial firms as well as traditional employers such as ABS and shipbuilders. 


\section{Appendix B Findings}

\section{Industry feedback}

The visits to industry were very positive in support on the proposed program to support research and education in Navy NA \& ME. The value of a naval architect in the firms contacted was considered very high. It was not necessary to have large numbers in any firm, but their skills in seeing the whole design and being able to make trade-offs and compromises was considered indispensable. It was the opinion of industry contacts that there is no engineer better than a Naval Architect to deal with the tradeoffs involved in the overall ship design. A subset of these, the very good ones, excel also in the overall design of systems other than ships. This opinion extended to the oil industry representatives who understood the contributions of the more traditional naval architect to offshore engineering.

There was strong support for the existence of a program in NA \& ME for education and research. Suggestions for work in areas relevant to their work were proposed. They are listed in table 2.

\section{Table 2 Areas Proposed for ONR Research by Industry}

- Marine materials \& environmental characteristics

- Improvements in vehicle subsystem technologies and system producibilities (cost reduction)

- Sensors (motion compensation with synthetic aperture

- Energy

- Autonomous control

- Other-actuators(eliminate), propulsion, life support

- System effectiveness model

- Evaluate configuration changes

- Identify high payoff operations

- UUV networks

- Deployment

- Interaction, communications and control

- System design and integration

- Automation (and its appropriate use)

- Materials

- New materials in new applications

- $A U V s$

- Design for affordability

- Electromagnetic signature

- Advanced control systems

- Hardware/software integration

- Shock analysis 
- Analysis of composite structures

- Analysis of high-strength steels, titanium and other alloys, and composites in marine applications

- Development of design tools that can halve the cost of performing a combatant ship design

- Acoustic design modeling on real-time basis

- Human factors interface, particularly with regard to seeing the combat picture clearly on real-time basis (don't make the operator be the integrator of the data and the synthesizer of the data into information.

\section{Briefings/Professional Societies}

There was considerable discussion and opinion expressed at the various briefings and meetings to stimulate this interchange. Support for the general concept of ONR taking the lead in creating a program in navy NA \& ME was unanimous. There was far less consensus on exactly what form such a program should take. No new areas of potential research beyond those listed above emerged. The general sense was that there was a demand for students graduating in NA \& ME, at all levels, but particularly in quantity at the undergraduate level.

Recommendations were offered to establish a broad program that would support for faculty who are currently at schools in the field. Support for faculty engaged in applied research should be included. Narrowly defining a research area was considered to be limiting and inconsistent with fostering a broader level of health to academic programs in the field.

In considering a regular (annual) meeting of educators in the field, it was recommended that the model established in the aeronautics industry be followed. An entity is in place in this industry called the Industry-University-Government Roundtable for Enhancing Engineering (IUGREE).

Another recommendation that came out of earlier meetings was to meet with members of the Defense Science Board. The sense of the recommendations from that meeting was to accept the reality of the navy being the major, if not only, player in the shipbuilding business and accept such a program in support of navy NA \& ME as necessary and appropriate. Definition of the contents of such program could benefit from review by similar independent and knowledgeable people such as present at this meeting. Creating an advisory panel that would meet with the ONR sponsor at regular intervals and offer discussion and stimulation and recommendations for areas to pursue with sponsored research.

\section{Department of Commerce Study}


The study is still in progress as of the writing of this report. Current status can be found at http://www.doc-bxa.bmpcoe.org/news/news-maritime.html. Reference 14 reported interim results. Completed surveys have been received by the Department of Commerce and shared with us. 180 surveys were returned yielding useable response from 144 companies, representing approximately $90 \%$ of revenues in the industry. The data reporting annual maritime related hours shows a steady level of employment of naval architects, marine engineers and other marine professionals for the past few years and is estimated to remain approximately level for the near term. There are about one third as many naval architects, marine engineers below thirty years of age $(\sim 1,000)$ compared to ages between 30-40 and 40-50. About 10 firms report shortages of naval architects and marine engineers while about 20-50 have shortages in the skilled production trades including welders ship fitters etc. About 50 firms feel their business has been impacted by these shortages.

Research and development expenditures have been steady for the years 1996-98 at approximately $\$ 300 \mathrm{M}$, but are predicted to fall off significantly due to a steep reduction in development in the years 1999-2000. The Navy is the largest source of R\&D funding but is declining significantly from $1996(\$ 200 \mathrm{M})$ to 1998 (\$100M). It is being replaced by U.S. private entities. To assess maritime technology and development needs companies self assessed their relative strength in a wide spectrum of categories. Not all firms require capability in all areas. The number of companies considering themselves to be weak in indicated areas is shown in descending order in Appendix E. It is important to note that the areas indicated by the most companies as a weakness in the technologies in the fundamental NA\&ME disciplines.

It can be seen that the areas that would be addressed by a program in navy NA \& ME could contribute to reducing the weaknesses cited in this study.

\section{Educational Statistics}

Without considerable effort, it is not possible to determine the number of graduates with the appropriate skills to carry the designation of naval architect in the context of this study. The Department of Education statistics for degrees awarded in 1995-96 show a total of 503 bachelor degrees awarded in both NA \& ME and OE. 336 bachelor degrees were categorized as NA \& ME, but many of those were degrees in Marine Engineering or Marine Engineering Systems. The program at Maine Maritime Academy, the largest granter of bachelor degrees in NA \& ME is more oriented towards marine engineering. A total of 119 degrees in NA \& ME were awarded by universities accredited by ABET in either Naval Architecture or Naval Architecture and Marine Engineering. Even this does not indicate the total picture as VPI is accredited in Ocean Engineering, but the program is more oriented towards NA \& ME. At MIT, with appropriate selection of electives it is possible to graduate with the skills of a naval architect.

The majority of bachelor degrees in NA \& ME in 1995-96 (249 of 335) were awarded by military or state maritime academies. While some of the military graduates will be part of the knowledge infrastructure in NA \& ME, if not immediately then after retirement or 
separation from the military, many will be performing other operational functions, in any event not available to industry. The state maritime academies will provide many graduates available to industry given the low requirement for sea going officers.

In light of these factors, it is not possible to determine the exact number of naval architect graduates available for employment in the industry. It is likely greater than the nonmilitary or maritime academy and accredited in NA or NA \& ME degrees awarded number of 70 (Univ. of Michigan, Univ. of New Orleans and Webb Institute). It is certainly far less than the 600 naval architects reported graduated in Korea.

The data from MIT, University of Michigan, Webb Institute, University of New Orleans, and Virginia Polytechnic Institute from 1996 to present indicates an increase in bachelor degrees. A decline in graduate degrees largely due to the decline in degrees from MIT has also occurred. As with the bachelor degrees, advanced degrees in OE may be part of the naval architecture infrastructure, depending on the specific area of study and undergraduate education of the graduate.

Modeling of the system comprised of undergraduate education, graduate school, industry employment and faculty resulting from a fraction of the doctoral degrees awarded was explored with Pugh-Roberts, a company with experience in developing such models. After extensive discussion, it was concluded that such a model could have applicability at a higher level than the specific application to the question of NA\&ME. The value of the model for this issue is minimal due to the size of the problem (small numbers). The issue boils down to 1 to 5 faculty conducting research in a specific discipline producing a similar number of doctor degrees per year. To see a cause and effect quantitatively would require a large and complex model to capture all the participants and feedback loops even though the numbers are extremely small. These loops are extensive and have strong closed loop feedback. The error band is likely to be larger than the data. This effort was not recommended for pursuit. 



\title{
Appendix C National Security Assessment of the Maritime Industry Survey Contents
}

\author{
Definitions (page v) \\ PART I - FIRM IDENTIFICATION (pages 1-3) \\ 1. Company Name and Address \\ 2. Ownership \\ 3.Establishment Information \\ 4. Mergers and Acquisitions
}

PART II- EMPLOYMENT INFORMATION (pages 4-6)

1.Annual Workforce Hours

2.Age Distribution of Current Maritime-Related Work Force

3.Labor Skill Shortages

4.Employment of Non-US Citizens within Current Work Force

5.Impacts of Labor Shortages

6. Training Programs

7. Other labor Concerns

PART III- FINANCIAL PERFORMANCE (page 7)

1. Maritime Revenues and Income

2.Maritime Financial Data

3. Maritime New Investment

PART IV - MARITIME TECHNOLOGY (pages 8-10)

1.Research and Development

2. Maritime Technology and Development Needs (Part 1)

3. Maritime Technology and Development Needs (Part 2)

4. Teaming with Other Organizations

PART V - COMPETITIVE FACTORS AND BENCHMARKING (pages 11-13)

1.Competitive Prospects

2.Past Actions to Improve Competitiveness

3.Future Plans to Improve Competitiveness

4.U.S. Government Assistance

5.Productivity

6.Export Opportunities

7.Effect of Declines in Defense Expenditures

8.Effects of Other Government Expenditures

9. Competitive Status Benchmark

PART VI- SUPPLIER INFORMATION (pages 14-15)

1.Material and Supply Leadtimes

2.Foreign Sourcing

3.Major Supplier Identification

CERTIFICATION (page 16)

General Comments

From: National Security Assessment of the Maritime Industry, Industry Survey: Building and Repairing of Ships, Boats, and Other Marine Platforms, A Joint Project Between the U.S. Department of Commerce, Bureau of Export Administration and the U. S. Department of the Navy, Naval Surface Warfare Center, Carderock Division. September 1999 


\section{Appendix D Educational Data}

Bachelors degrees awarded in NA \& ME and Ocean OE are shown in Figure 2. Figure 3 shows the masters degrees awarded and Figure 4 shows doctors degrees awarded during the period indicated. Ocean Engineering (OE) degrees are include as many schools that offer Ocean Engineering degrees do graduate individuals with NA \& ME skills. It should be noted, however, these numbers of degrees are upper limits on the graduates with NA $\&$ ME skills as some OE graduates have skills more oriented towards other ocean related disciplines.

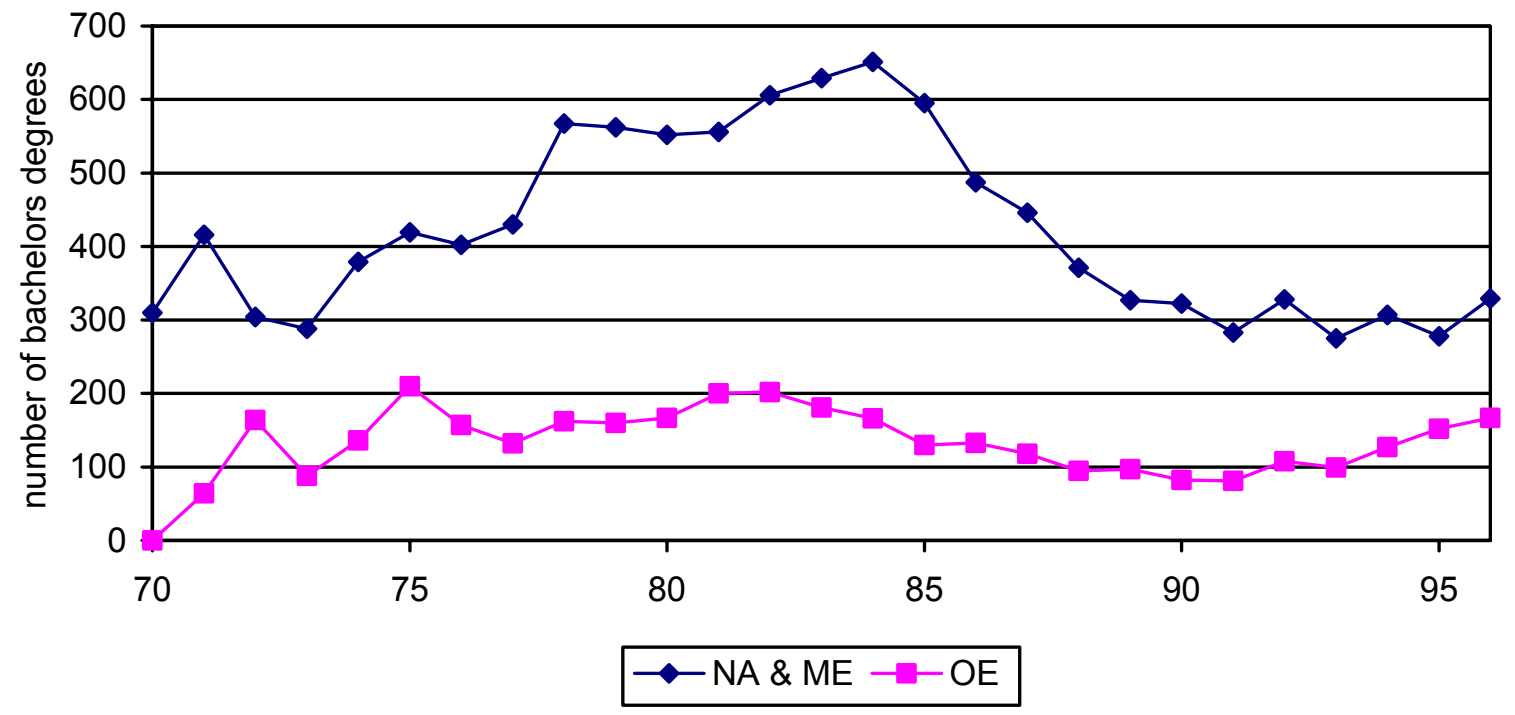

Figure 2 Bachelors Degrees Awarded 1969-96 


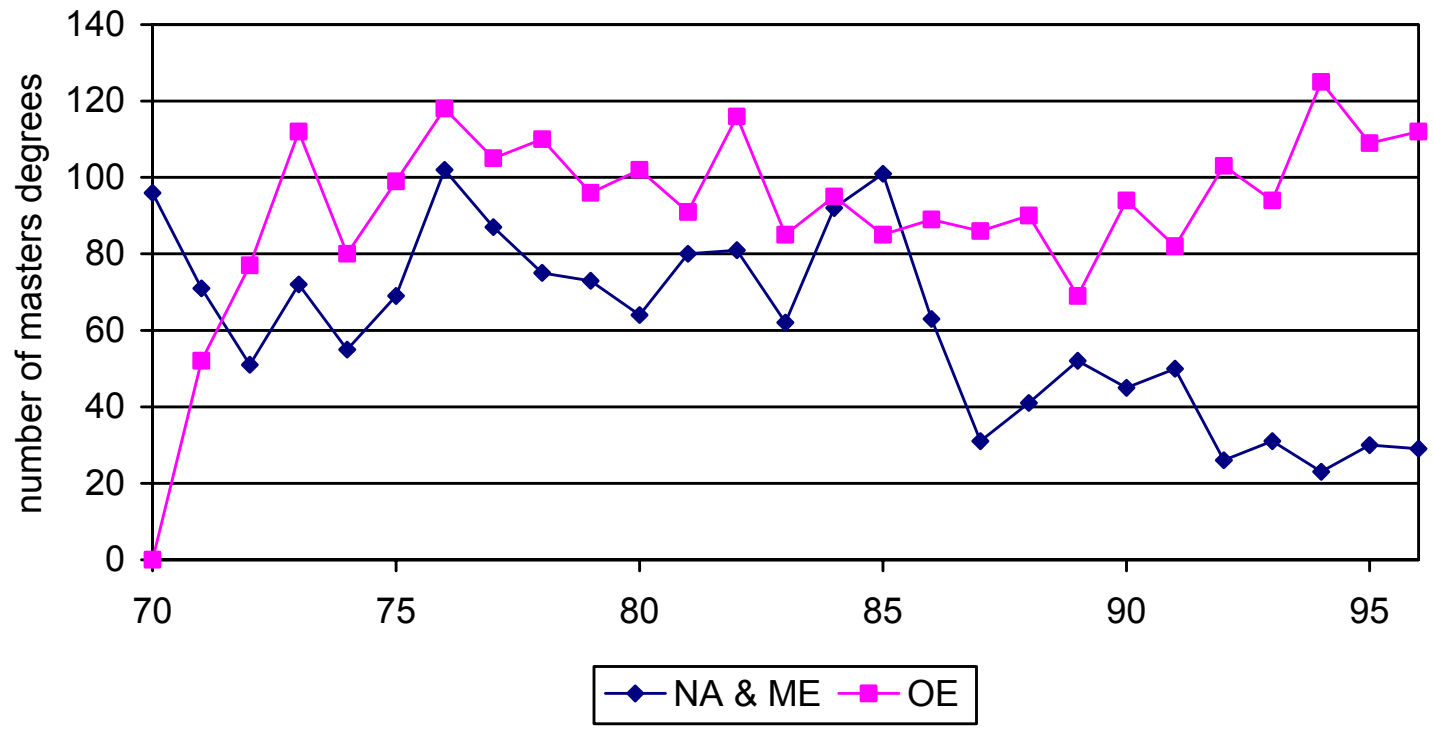

Figure 3 Masters Degrees Awarded 1969-96

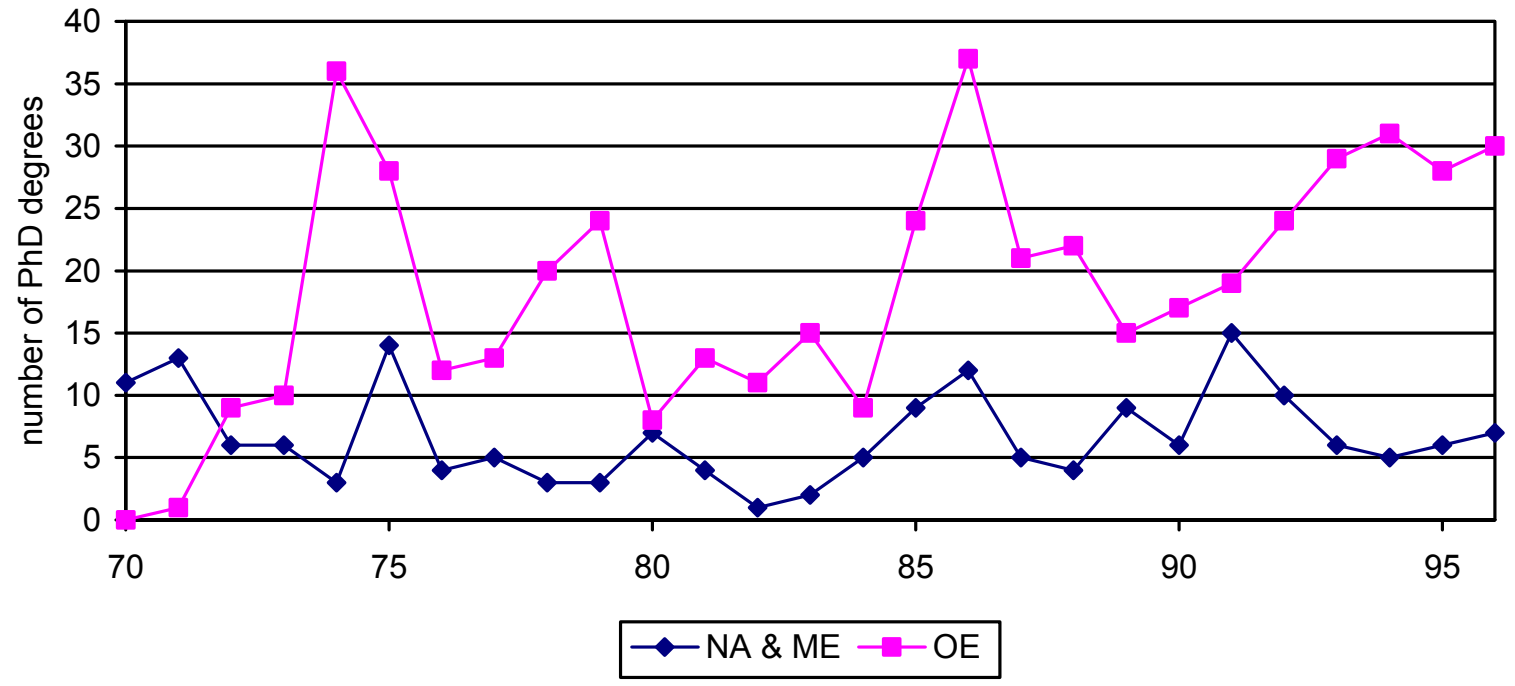

Figure 4 Doctors Degrees Awarded 1969-96.

The National Science Foundation also compiles statistics on degrees awarded and enrollment universities in the U.S. For example, reference 15 provides data on doctors degrees awarded from 1988 through 1997 but in 1991 deleted naval architecture/marine engineering as a subfield and all subsequent information is lumped in the category of other or "n.e.c." not elsewhere classified. Reference 16 shows both NA \& ME enrollments as n.e.c. 
To indicate the sources of the NA \& ME and OE graduates, a breakdown of the degrees awarded by university for the latest year available was requested from the Department of Education. They were very cooperative and provide the breakdown requested by e-mail, reference 17.

NA \& ME degrees by university for the year 1995-96 are shown Table 3 and OE degrees awarded are shown in Table 4.

Table 3 NA \& ME degrees awarded in 1995-96

NA \& ME degrees awarded 1995-96

MAINE MARITIME ACADEMY

U.S. MERCHANT MARINE ACADEMY

MASSACHUSETTS MARITIME ACADEMY

UNIVERSITY OF MICHIGAN-ANN ARBOR

UNIVERSITY OF NEW ORLEANS

SUNY MARITIME COLLEGE

U.S. COAST GUARD ACADEMY

WEBB INSTITUTE

U.S. NAVAL ACADEMY

VIRGINIA POLYTECHNIC INSTITUTE

UNIVERSITY OF WISCONSIN-MADISON

TEXAS A \& M UNIVERSITY-GALVESTON

UNIVERSITY OF CALIFORNIA-BERKELEY

Bachelors Masters Doctors

79

68

53

31

23

22

4

18

17

16

14

7

5

4

1

6

3

Table 4 OE degrees awarded 1995-96

\section{OE degrees awarded 1995-96}

U.S. NAVAL ACADEMY

FLORIDA ATLANTIC UNIVERSITY

TEXAS A \& M UNIVERSITY

FLORIDA INSTITUTE OF TECHNOLOGY

TEXAS A \& M UNIVERSITY-GALVESTON

MIT

UNIVERSITY OF RHODE ISLAND

UNIVERSITY OF FLORIDA

STEVENS INSTITUTE OF TECHNOLOGY

UNIVERSITY OF NEW HAMPSHIRE

UNIVERSITY OF HAWAII AT MANOA

GEORGE WASHINGTON UNIVERSITY

\section{Bachelors Master Doctors \\ Degrees Degrees}

69

$29 \quad 11 \quad 5$

$29 \quad 9 \quad 2$

$\begin{array}{lll}21 & 7 & 1\end{array}$

11

5

3

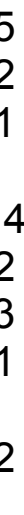

As the readily available data from the Department of Education is a few years old, current information was obtained by e-mail (references 18 to 22) from MIT, University of Michigan, Webb Institute, University of New Orleans, and Virginia Polytechnic Institute 
as indicators of current trends. Bachelors degrees, masters degrees and doctors degrees from 1997 to present are shown in Table 5, Table 6and Table 7 respectively. Estimates for bachelors degrees in 2000 and 2001 are based on numbers of seniors and juniors in the undergraduate programs.

Table 5 Bachelors degrees 1996-97 to 2000-01

$\begin{array}{lcccccc}\text { Bachelors degrees } & 95-96 & 96-97 & 97-98 & 98-99 & \begin{array}{c}\text { est. 99- } \\ 00 \\ \text { (seniors) }\end{array} & \begin{array}{c}\text { est. 00- } \\ \text { (juniors) }\end{array} \\ \text { Michigan } & & & & & & \\ \text { UNO } & 34 & 28 & 21 & 20 & 31 & 29 \\ \text { Webb } & 23 & 10 & 16 & 11 & 32 & 18 \\ \text { VPI } & 16 & 19 & 19 & 21 & 15 & 19 \\ \text { MIT } & 7 & 6 & 9 & 11 & 26 & 12 \\ \text { MIT } & 5 & 2 & 6 & 6 & 4 & 5\end{array}$

Table 6 Masters degrees 1996-97 to 1998-99

\begin{tabular}{|c|c|c|c|c|}
\hline $\begin{array}{lr}\text { Masters } & \text { (incl. } \\
\text { Engineers) degrees }\end{array}$ & $95-96$ & $96-97$ & $97-98$ & $98-99$ \\
\hline MIT & 52 & 41 & 31 & 26 \\
\hline Michigan & 29 & 19 & 32 & 33 \\
\hline UNO & 2 & 7 & 3 & 4 \\
\hline Webb & 0 & 7 & 0 & 7 \\
\hline VPI & 1 & 2 & 3 & 1 \\
\hline
\end{tabular}

Table 7 Doctors degrees 1996-97 to 1998-99

$\begin{array}{lcccc}\text { Doctors degrees } & 95-96 & 96-97 & 97-98 & 98-99 \\ \text { MIT } & 14 & 18 & 10 & 8 \\ \text { Michigan } & 4 & 3 & 3 & 6\end{array}$

The emphasis in this study is on NA \& ME while the degrees have been reported in both NA \& ME and OE. To help sort out the NA \& ME degrees, the Accreditation Board for Engineering and Technology (ABET) certified programs in NA \& ME and OE are listed in Table 8. These were obtained from SNAME (reference 23) who coordinates the ABET activities in these areas. 
Table 8 ABET certification of programs

Marine Engineering
State University of New York Maritime College
US Naval Academy
Marine Engineering Systems
US Merchant Marine Academy
Marine Systems Engineering
Maine Maritime Academy
Maritime Systems Engineering (Ocean Engineering)
Texas A\&M Galveston
Naval Architecture
State University of New York Maritime College
US Naval Academy

Naval Architecture and Marine Engineering

University of Michigan

University of New Orleans

US Coast Guard Academy

Webb Institute

Ocean Engineering

Florida Atlantic University

Florida Institute of Technology

University of Hawaii at Manoa (MS level)

MIT

University of Rhode Island

Texas A\&M University

US Naval Academy

Virginia Polytechnic Institute and State University 


\section{Appendix E Number of Companies Indicating Technology Weakness}

These were data reported in response to the department of commerce survey by companies in the ship and boat building industries.

Maritime Technology Category

(from reference 14)

Number

indicating

weakness

16. Naval Architecture and Integrated Ship Design and Support 16

17. Shipbuilding and Manufacturing Technology 16

20. Logistical Support Systems 13

3. Noise Abatement and Quieting Systems and Components 11

11. Hull Forms and Propulsors Systems and Components 11

12. Material and Applications 11

19. Environmental Quality Sciences Systems 11

7. Electrical Machinery Systems and Components 9

1. Cost Estimating/Cost Benefit Analysis 8

2. Safety/Vulnerability and Survivability System and 8

Components

10. Undersea Vehicle Deployed Systems and Components 8

8. Cargo Handling/Hull and Deck Machinery Systems and 7 Components

18. Analytical and Experimental Aerodynamics 7

9. Habitability and Outfitting Systems and Components 6

4. Electromagnetic Signature and Silencing Systems and 5 Components

5. Propulsion and Energy Systems and Components 5

6. Auxiliary Machinery Systems and Components 5

13. Structural Systems and Components 5

15. Amphibious and Land-Based Vehicles Systems and 5 Components

21. Electrochemical Power Systems and Components 4

14. Small Craft Systems and Components 2 